\title{
Mucin producing carcinoid tumours of the vermiform appendix
}

\author{
M. T. HAQQANI ${ }^{1}$ AND GEORGE WILLIAMS
}

From the Department of Pathology, Stopford Building, The University, Manchester M13 9PT

SUMMARY Six cases of an unusual mucoid variant of carcinoid tumour of the appendix are reported. These lesions are small, detected incidentally, and carry a good prognosis. Their histological features are distinctive and differ from those of ordinary carcinoid tumours and adenocarcinoma. They have been confused with adenocarcinoma, sometimes resulting in radical surgery. Surgery beyond appendicectomy is probably unwarranted in these cases. The mucin secreted by goblet cells of the normal mucosal epithelium and by the cells of these carcinoid tumours have certain histochemical similarities.

Carcinoid tumour and adenocarcinoma are the most common primary neoplasms of the appendix. Carcinoid tumour in its ordinary form is well recognised and documented. We describe here six cases of an unusual variant of carcinoid tumour of the appendix with distinct histological features which differ from both ordinary carcinoid tumour and adenocarcinoma. Such tumours have been called 'goblet cell carcinoid' by Subbuswamy et al. (1974) and 'mucinous carcinoid tumour' by Klein (1974). The infiltration with small acini and 'signet-ring' cells which characterise this variant has led to the diagnosis of adenocarcinoma sometimes resulting in radical surgery. They are usually located near the tip of the appendix, detected incidentally, and contain an appreciable number of argentaffin, argyrophil, and Paneth cells detectable in formalinfixed tissue. Their unique histological features and innocent clinical course support the concept that such lesions represent mucinous variants of appendiceal carcinoid tumour, and the need for any additional surgery beyond appendicectomy is probably unwarranted.

\section{Material and methods}

Six cases of microglandular mucin-producing carcinoid tumours diagnosed within the period 1964-76 were collected from four Manchester hospitals. Twenty-two appendicular carcinoids

'Present address: Walton Hospital, Rice Lane, Liverpool L9 1AE

Received for publication 4 October 1976 reported in the corresponding 12 years at Manchester Royal Infirmary were reviewed to assess mucin secretions. Tissue in all cases was fixed in $10 \%$ formalin. Sections were stained by haematoxylin and eosin, PAS, and diastase pretreated PAS and by a diazo method for argentaffin granules, Bodian's protargal method for argyrophil granules and by modified Alcian Blue technique (Scott and Dorling, 1965) for acid mucopolysaccharides. The last method is based on a selective uptake of Alcian Blue by anionic groups of acid mucopolysaccharides in the presence of critical concentrations of electrolyte $\left(\mathrm{Mg} \mathrm{Cl}_{2}\right)$ added to the dye solutions.

The following is a brief clinical summary and findings in each case.

\section{CASE 1}

A 46-year-old man presented with colicky pain in the right iliac fossa. A tender mass was diagnosed as an appendicular abscess. This subsided with antibiotic treatment. The appendix was removed six weeks later and showed no significant macroscopic abnormality.

Histology Examination of a longitudinal section through the tip of the appendix revealed a microacinar, mucin-producing carcinoid infiltrating from the base of the mucosal glands to the deep muscular layer. It was very well differentiated. The hallmarks of colonic adenocarcinoma-namely, pleomorphism, mitotic activity, and tissue destruction or necrosis-were conspicuous by their absence. The patient is alive and well nine years after the operation. 
CASE 2

A 52-year-old woman presented in February 1968 with severe pain in the right iliac fossa. The appendix when removed appeared inflamed and thickened in the distal half with total occlusion of the lumen. Histologically acute appendicitis was confirmed and a microacinar mucin-producing carcinoid infiltrating up to the serosa was also noted. The patient was well until November 1975, when she noticed distension of the lower abdomen. In March 1976 massive bilateral ovarian tumours (total weight $2 \mathrm{~kg}$ ) were removed. These were reported as Krukenberg tumours possibly secondary to carcinoma of the stomach.

Histology Review of the appendiceal and ovarian neoplasms showed a common denominator of 'signet-ring' cells and mucin production. The appendiceal neoplasm, however, showed a regular microacinar pattern in which the signet-ring cells lacked pleomorphism and mitoses. In the ovarian neoplasm abnormal mitosis and pleomorphism of the nuclei of signet-ring cells was associated with the usual variety of adenocarcinoma. When last seen in August 1976 the patient's condition was satisfactory.

\section{CASE 3}

A 23-year-old woman was admitted for chronic pelvic inflammatory disease of one year's duration which had not responded to antibiotic treatment. The appendix and both fallopian tubes were removed. Pyosalpinx of the fallopian tubes was confirmed. The appendix appeared normal.

Histology Histological examination of the appendix showed a mucinous carcinoid tumour similar in appearance to the other cases and penetrating to the deep muscular layer. The patient remains well six months after the operation.

\section{CASE 4}

A 60-year-old man, referred to the urological clinic because of haematuria of two months' duration, was found to have a lower urinary tract obstruction. Bladder biopsy was followed by cystectomy for a large papillary tumour; prostatic tissue and a normal looking appendix were also received for examination.

Histology Examination confirmed a transitional cell carcinoma of the urinary bladder, benign prostatic hyperplasia, and a mucinous carcinoid tumour of the appendix identical with other cases. The patient died two years later from carcinomatosis due to carcinoma of the urinary bladder.
CASE 5

A 42-year-old woman presented with abdominal discomfort and pain in the right iliac fossa of one week's duration. Appendicectomy was carried out for 'acute appendicitis'. The distal $2 \mathrm{~cm}$ looked slightly thickened.

Histology Microscopical examination showed a mucinous carcinoid tumour, similar to that in the other cases, infiltrating up to the serosa. The patient's condition six months after the operation was satisfactory.

CASE 6

A 60-year-old woman was admitted in February 1964 for pain in the abdomen. A mass in the right iliac fossa was diagnosed as an appendicular abscess and treated with antibiotics. Subsidence of the mass was followed by appendicectomy. The distal third of the appendix was thickened up to a maximum diameter of $2.5 \mathrm{~cm}$.

Histology Examination showed a tumour similar to other cases. The patient had had a subtotal hysterectomy for menorrhagia in 1948 (sections and report not available) and a right mastectomy in 1956 for a poorly differentiated spheroidal cell carcinoma of the breast which bore no similarity to the appendicular neoplasm removed in 1964 . Her ill health continued after the appendicectomy. She was admitted in September 1967 for masses in the lower abdomen and died soon afterwards. Since no biopsy or necropsy was carried out death was presumed to be due to carcinomatosis of mammary origin.

\section{Results}

The slight to moderate macroscopical thickening of the distal third of the appendix in three cases evoked no suspicion of neoplasm. In three other cases the appendix appeared normal. The appendix was inflamed in only one case. All the tumours were small and showed no yellowish discoloration in the formalin fixed state. Final diagnoses required histological examination in all cases.

All tumours presented remarkably similar histological appearances of well differentiated microacini and cellular rosettes infiltrating the base of the mucosal glands (Fig. 1) or the deeper muscle layers (four cases) (Fig. 2) and as far as the serosa in two cases. There was no stromal reaction. In some cases (Table 1) the dominant picture was that of cellular rosettes and clusters lacking a central lumen; cytoplasm was distended with mucin, giving a vacuolated appearance. Nuclei were basal, small, ovoid, and regular with delicate nuclear membranes 


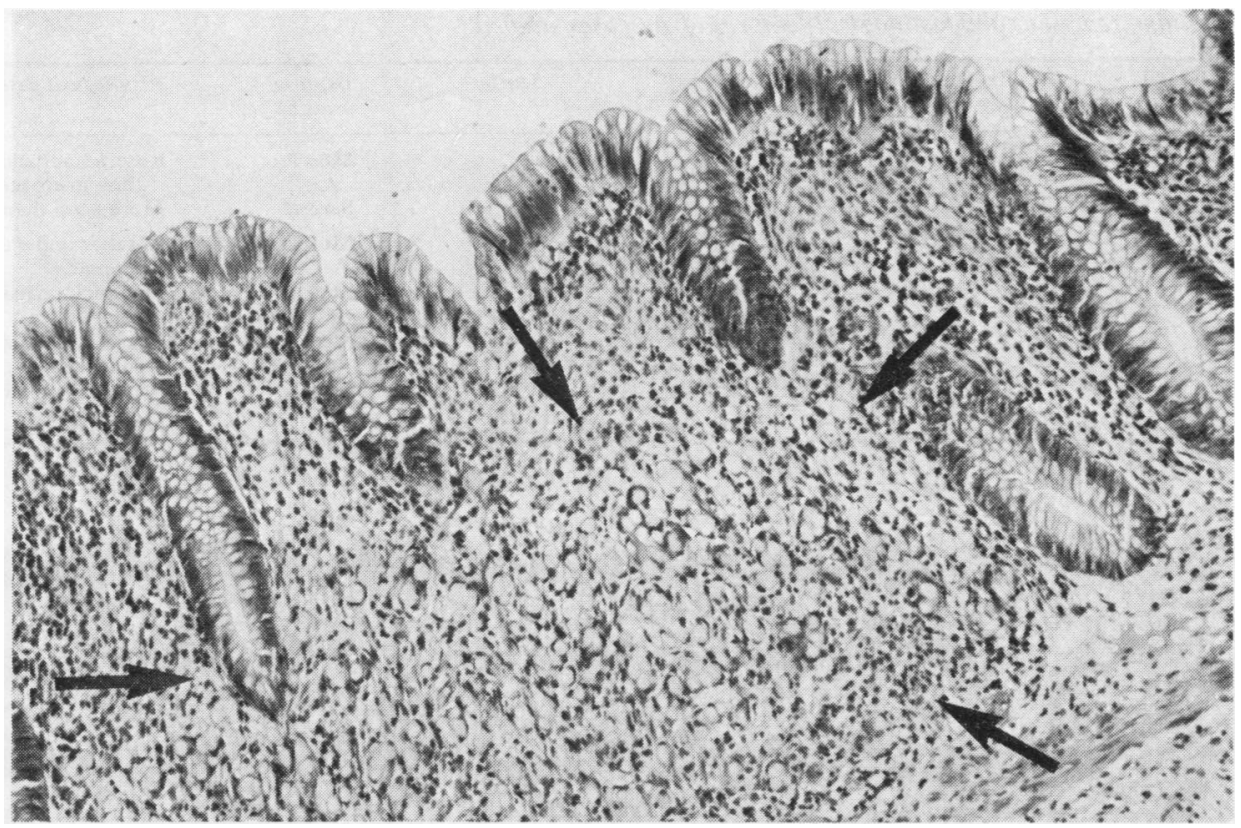

Fig. 1 Clusters and rosettes of tumour cells in the lamina propria outlined by arrows. ( $H$ and $E \times 100)$

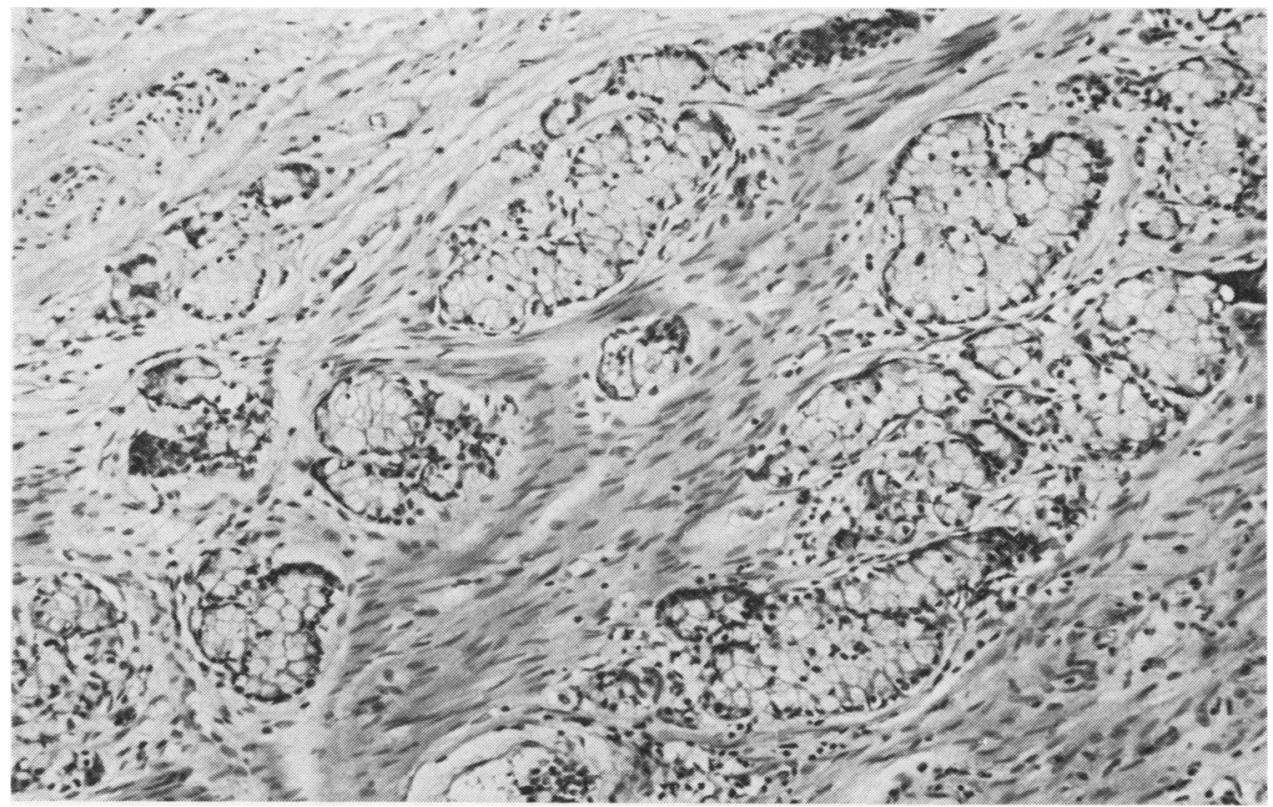

Fig. 2 Microacinar pattern. Small well differentiated glands infiltrating the muscular layer (case 2). (H and $E \times 100)$ 
Table 1 Staining reactions and histological features of six cases studied

\begin{tabular}{|c|c|c|c|c|c|c|}
\hline Case & Argentaffin cells & Argyrophil cells & $\begin{array}{l}\text { Paneth cell } \\
\text { incidence }\end{array}$ & Mucin & $\begin{array}{l}\text { Depth of } \\
\text { invasion }\end{array}$ & Histological pattern \\
\hline 1 & Occasional & Occasional & Absent & + & Muscle & $\begin{array}{l}\text { Rosettes and clumps more } \\
\text { than microacini }\end{array}$ \\
\hline 2 & $+t+$ & $+t+$ & High & + & Serosa & More acini than rosettes \\
\hline 3 & + & + & Scanty & + & Muscle & $\begin{array}{l}\text { Rosettes and clumps more } \\
\text { than acini }\end{array}$ \\
\hline 4 & ++ & +++ & Moderate & + & Muscle & $\begin{array}{l}\text { Microacini equal to } \\
\text { rosettes }\end{array}$ \\
\hline 5 & + & +++ & High & + & Muscle & $\begin{array}{l}\text { Microacini equal to } \\
\text { rosettes }\end{array}$ \\
\hline 6 & Absent & Absent & Moderate & + & Serosa & $\begin{array}{l}\text { Acini fewer than rosettes } \\
\text { and clumps }\end{array}$ \\
\hline
\end{tabular}

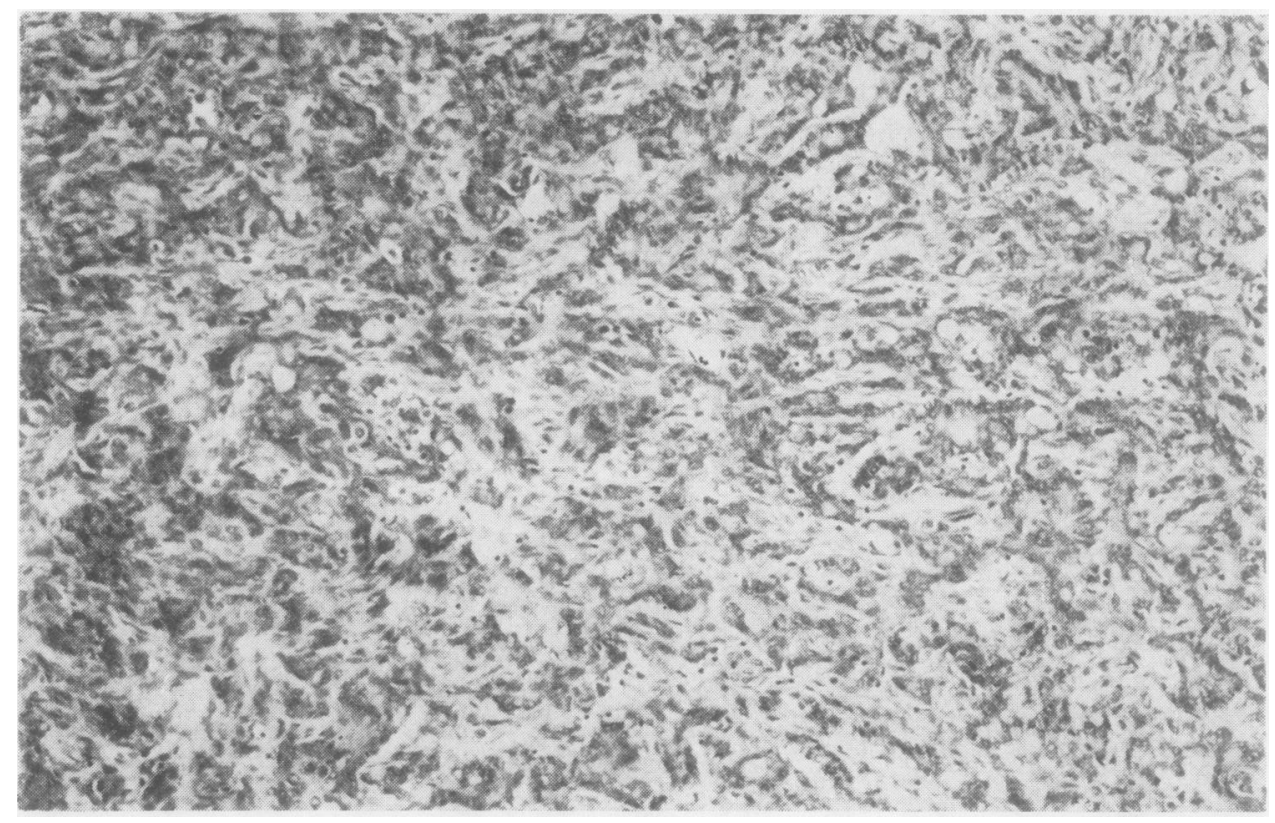

Fig. 3 Ovarian tumour from case 2 for comparison with appendicular neoplasm in Fig. 2. (H and E $\times 100)$

and finely dispersed chromatin. There was no pleomorphism and mitoses were generally absent. Characteristic solid nests of non-mucinous carcinoid cells were not present, and transition from solid to mucin-producing cells, as observed by Dische (1968) and Hernandez and Reid (1969) was observed in one small focus only in case 2 . The ovarian tumour from case 2 is shown (Fig. 3) for comparison with the appendicular neoplasm (Fig. 2).

The acid mucopolysaccharides in the tumours were studied in four cases by the technique of Scott and Dorling (1965). It was noted that Alcian Blue binding by the mucin of the normal mucosal goblet cells and of the carcinoid occurred in $0.2 \mathrm{M}$ concentrations of electrolyte (Fig. 4) but ceased at ${ }^{\circ}$ $0.6 \mathrm{M}$ concentrations, at which level only the sul- $N$ phated heparitin of adjacent mast cells retainedw the dye (Fig. 5).

Review of carcinoid tumours of the appendixo reported during the period 1964-76 at Manchesterø Royal Infirmary (excluding the cases included in the? present study) showed no evidence of mucin pro- -0 duction or a microacinar pattern.

\section{Discussion}

The histological features of these tumours are unusual. Some features-that is, microglandulano 


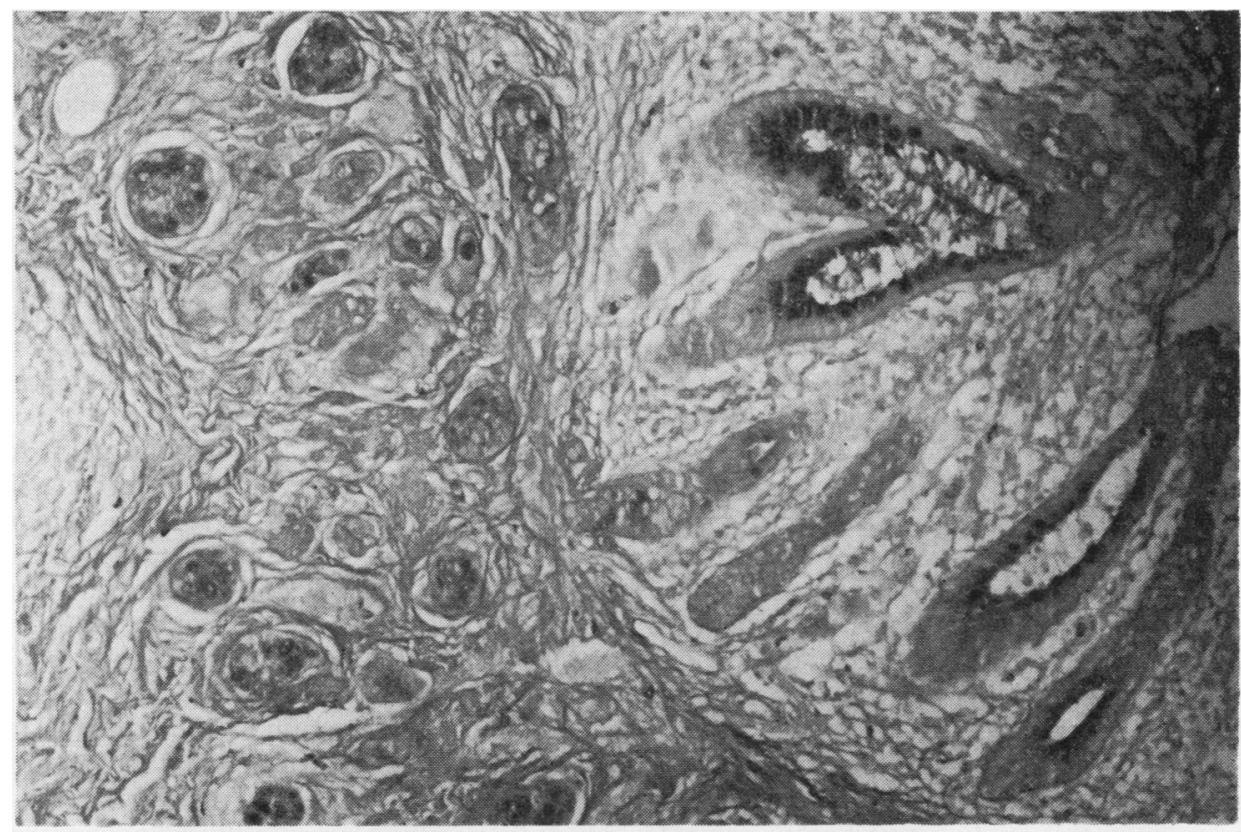

Fig. 4 Alcian Blue binding by the mucin of the normal mucosal goblet cells and of the carcinoid at $0.2 M$ concentration of the electrolyte. ( $H$ and $E \times 250$ )

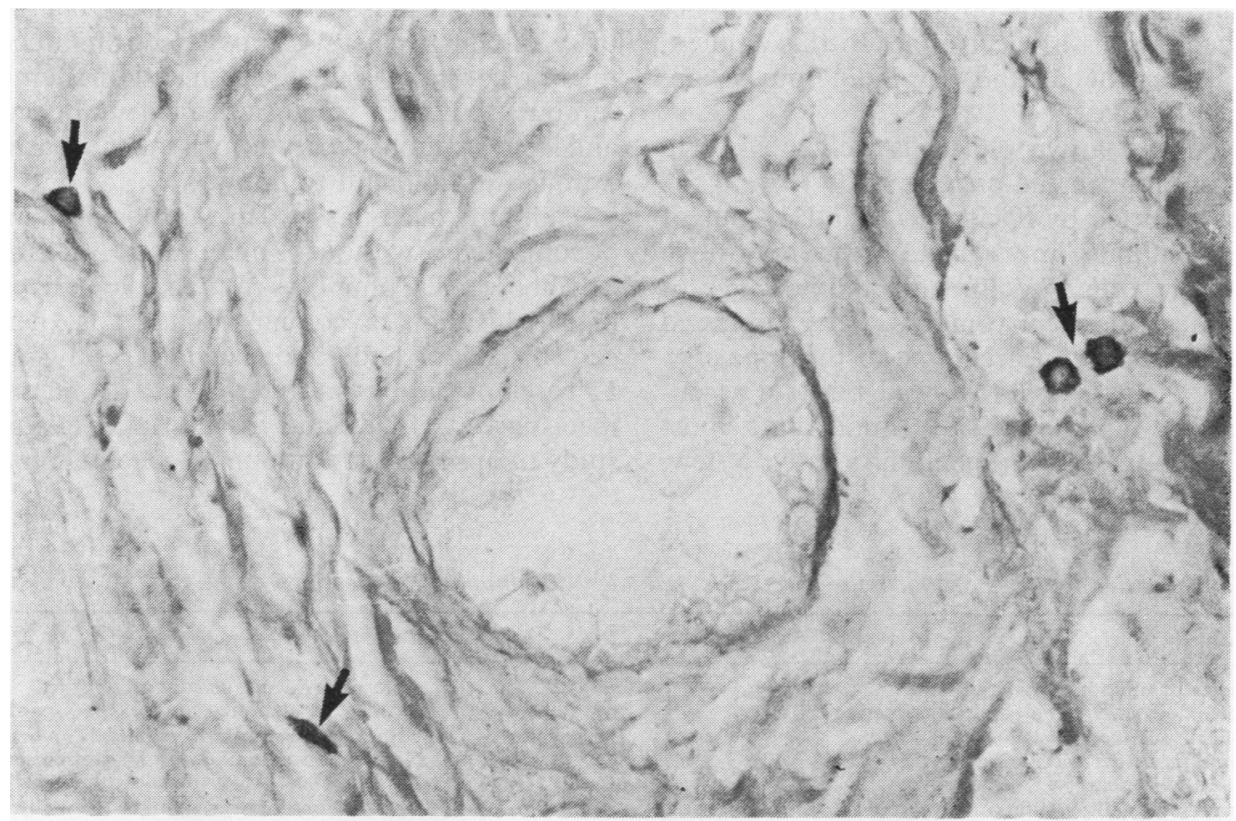

Fig. 5 Sulphated heparitin of mast cells (arrows) retain the dye at $0.6 \mathrm{M}$ concentration. Acinus in the centre not stained. (Alcian Blue $\times 250$ ) 
pattern, mural infiltration, and mucin secretionare shared with adenocarcinoma. The most important features of even well differentiated adenocarcinoma-for example, origin from mucosal glands, pleomorphism, and cellular atypia-are lacking however. Mucinous carcinoids of the appendix affect the base of the glands and infiltrate the lamina propria and other layers. The overall pattern of invasion without necrosis or destruction of tissue is strongly in favour of carcinoid tumour. The mucin secreting cells in these appendiceal neoplasms differ from the typical signet-ring cells of mucin-producing colonic adenocarcinomata in that the latter are characterised by irregular arrangement, nuclear pleomorphism, and abundant mitotic activity. In addition, Paneth cells do not feature in gastrointestinal mucin-producing adenocarcinomata (Subbuswamy et al., 1974) but they are prominent in mucinous carcinoids of the appendix. Similarities and differences between mucinous carcinoid and well differentiated adenocarcinoma of the appendix are listed in Table 2.

Histochemical investigation of the mucin content of the carcinoids in this study, using Scott's critical electrolyte concentration $\left(\mathrm{Mg} \mathrm{Cl} \mathrm{Cl}_{2}\right)$ in the dye solution, showed that the mucin of both normal mucosal goblet cells and of the carcinoid tumour cells reacted in a comparable manner. Both behaved as carboxylated acid mucopolysaccharides in contrast to the sulphated heparitin in adjacent mast cells, which retained Alcian Blue positivity at much higher molar concentrations of electrolyte. In this context, therefore, the epithelial and carcinoid mucins are histochemically alike.

Argentaffin and argyrophil cells were present in all but one tumour in the present study (Figs 6, 7). Three cases reported by Klein (1974) and 11 out of 12 studied by Subbuswamy et al. (1974) were positive for argentaffin cells. Wolff and Ahmed (1976) reported almost identical tumours. They preferred to regard them as adenocarcinoma of the appendix. Only one of their 12 cases showed positive argentaffin granules. Dische (1968) found that most carcinoid tumours were argentaffin; only a few, generally tumours of a minute size, were nonargentaffin. Failure or difficulty to demonstrate argentaffin cells in small mucinous carcinoid tumours is hardly surprising, since a subgroup of nonargentaffin carcinoid tumours is now well recognised. Hernandez and Reid (1969) described transition from carcinoid to columnar cell adenocarcinoma with lymph node metastasis of carcinoid pattern. They postulated that this unexpected variation in morphology and function of cells, which is determined genetically, may result from derepression of latent information in neoplasia.

The demonstration of argentaffin cells does not, however, resolve the problem of classification entirely. Argentaffin cells have been demonstrated in typical gastric and colonic adenocarcinomata (Azzopardi and Pollock, 1963; Kubo and Watanabe, 1971). Additional structural features and behaviour of those tumours justifies the designation of adenocarcinoma. Soga et al. (1971) described a unique mucin-producing tumour of the stomach in which considerable numbers of argentaffin and argyrophil cells were present in the neoplastic glands-a lesion which they termed 'argentaffin cell adenocarcinoma'. No metastatic deposit was found in a total of 47 lymph nodes examined. Rosai and Rodriguez (1968) described an intramural mucin-secreting neoplasm of the appendix in which light microscopy failed to reveal argentaffin or argyrophil granules, but they classified the tumour as a carcinoid because of its ultrastructural dense round granules characteristic of Kultchitsky cells. Thus electron microscopy might resolve the issue of classification of ambiguous tumours, but their small size, incidental occurrence, and inconspicuous presentation render ultrastructural examination difficult to apply.

Tumours such as we are reporting are well documented without unanimous classification (Steinberg and Cohn, 1967; Wood, 1967). Irrespective of classification, a common feature is their innocent behaviour and good prognosis. Only one of the 12 cases of Subbuswamy et al. (1974) recurred and metastasized. Jones and Macfarlane (1976), in a study of appendiceal tumours in general, very briefly

Table 2 Comparative features of mucinous carcinoids and adenocarcinoma of appendix

\begin{tabular}{ll}
\hline Mucinous carcinoids & Adenocarcinoma \\
\hline External evidence of tumours usually absent & External evidence usually present \\
Rosettes, clumps, and microacini of mucin secreting cells & A different glandular and papillary pattern \\
No pleomorphism, scanty mitosis & Marked pleomorphism, abundant mitosis \\
Invasion without tissue destruction or necrosis & Tissue destruction and necrosis often seen \\
Paneth cells usually present & Paneth cells not a feature \\
Appreciable numbers of argentaffin and argyrophil cells in most cases & Argentaffin and argyrophil cells usually absent \\
Clinically benign course & Usually malignant \\
Recurrence most unusual after simple appendectomy & Recurrence not unusual
\end{tabular}




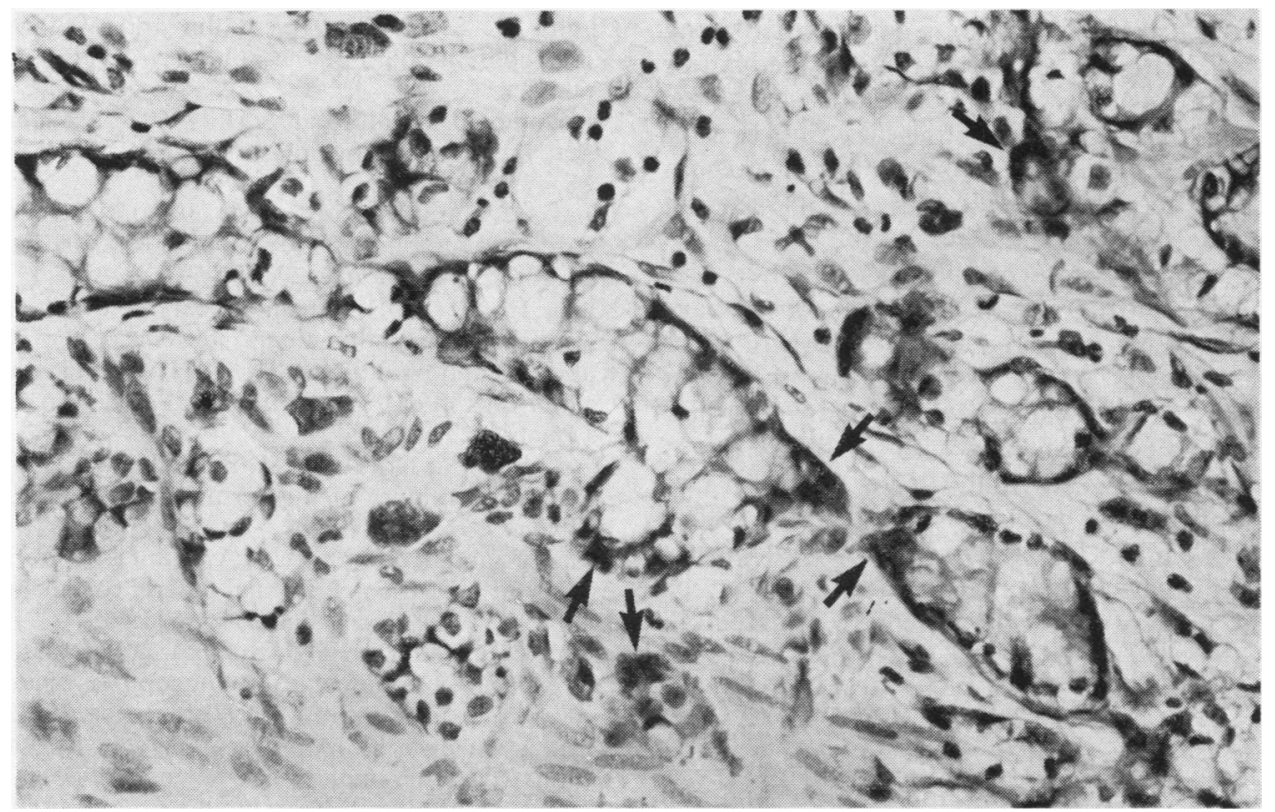

Fig. 6 Argentaffin cells (arrows) in the tumour acini. (Diazo $\times 250)$

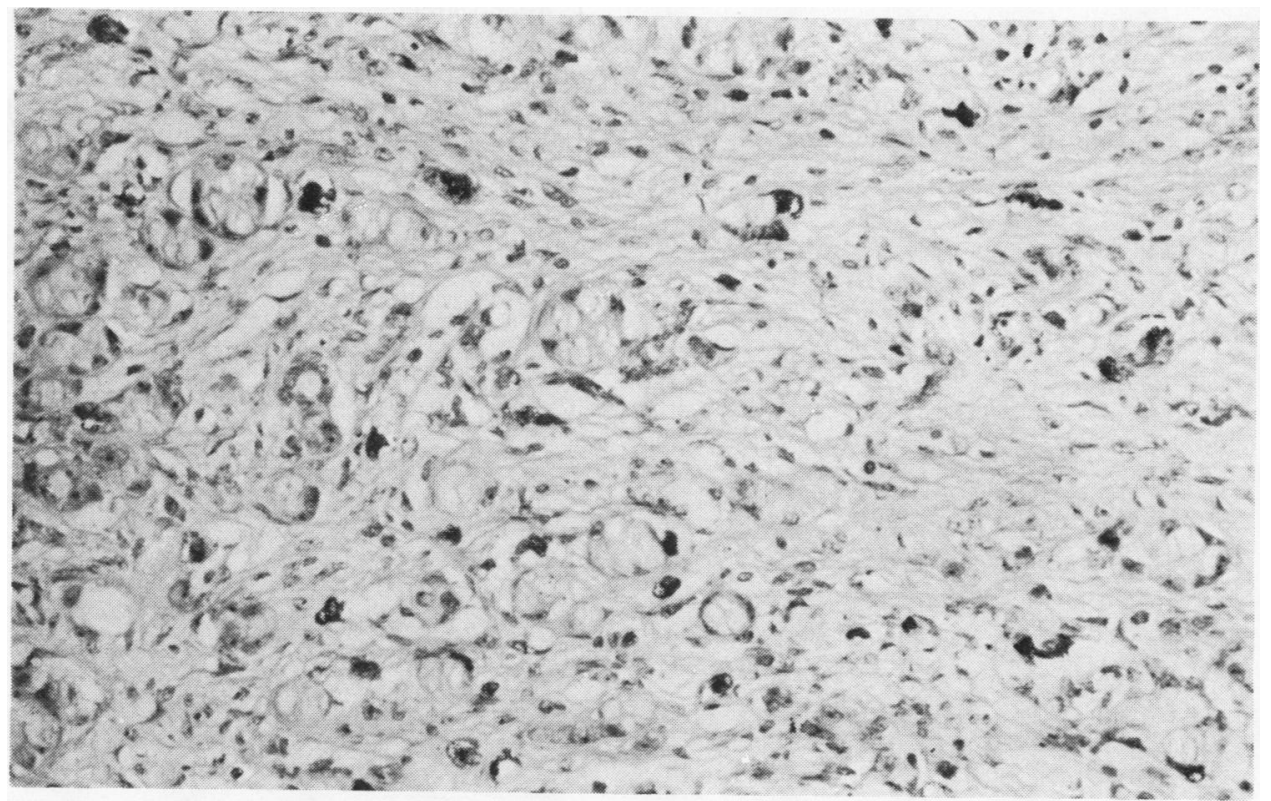

Fig. 7 Numerous argyrophil tumour cells react with protargol to produce dark cytoplasmic granules.

(Bodian $\times 250)$ 
mention four cases of mucinous carcinoids, in one of which peritoneal metastasis developed after appendicectomy. Normally appendicectomy is curative and right hemicolectomy is unnecessary unless the base of the appendix or adjacent caecum is invaded or, according to Moertel et al. (1968), the tumour exceeds $2 \mathrm{~cm}$ in diameter.

An interesting feature of the present study was the association in three of the six cases with primary carcinomas, which occurred either before or after the appendicular lesions. Two of the 12 cases reported by Subbuswamy et al. had a similar association. This is in keeping with the behaviour of carcinoids in general, in that 19 out of $144(13 \%)$ ordinary appendiceal carcinoids studied by Moertel et al. (1968) affected patients with histologically confirmed primary cancers. It cannot, however, be stated with certainty that the presence of a carcinoid tumour of the appendix indicates any increased tendency to the development of other malignant tumours.

We thank Dr J. Davson for supplying the material for cases 1, 2, and 6 and Dr R. Pell-Ilderton and Dr B. Peach for permission to use their cases for publication. We also thank Mr D. Bradley for technical assistance and the medical record departments of the Manchester Royal Infirmary, Bury General Hospital, and Salford Royal Infirmary.

\section{References}

Azzopardi, J. G. and Pollock, D. J. (1963). Argentaffin and argyrophil cells in gastric carcinoma. J. Path. Bact., 86, 443-451.
Dische, F. E. (1968). Argentaffin and non-argentaffin carcinoid tumours of the appendix. J. clin. Path., 21, 60-66.

Hernandez, F. J. and Reid, J. D. (1969). Mixed carcinoid and mucus secreting intestinal tumours. Arch. Path., 88, 489-496.

Jones, R. A. and Macfarlane, A. (1976). Carcinomas and carcinoid tumours of the appendix in a district general hospital. J. r:lin. Path., 29, 687-692.

Klein, H. Z. (1974). Mucinous carcinoid tumor of the vermiform appendix. Cancer (Philad.), 33, 770-777.

Kubo, T. and Watanabe, H. (1971). Neoplastic argentaffin cells in gastric and intestinal carcinomas. Cancer (Philad.), 27, 447-454.

Mcertel, C. G., Dockerty, M. B., and Judd, E. S. (1968). Carcinoid tumors of the vermiform appendix. Cancer (Philad.), 21, 270-278.

Rosai, J. and Rodriguez, H. A. (1968). Application of electron microscopy to the differential diagnosis of tumors. Amer. J. clin. Path., 50, 555-562.

Scott, J. E. and Dorling, J. (1965). Differential staining of acid glycosaminoglycans (mucopolysaccharides) by alcian blue in salt solutions. Histochemie, 5, 221-233.

Soga, J., Tazawa, K., Aizawa, O., Wada, K., and Tuto, T. (1971). Argentaffin cell adenocarcinoma of the stomach: an atypical carcinoid? Cancer (Philad.), 28, 999-1003.

Steinberg, M. and Cohn, I. Jr. (1967). Primary adenocarcinoma of the appendix. Surgery, 61, 644-660.

Subbuswamy, S. G., Gibbs, N. M., Ross, C. F., and Morson, B. C. (1974). Goblet cell carcinoid of the appendix. Cancer (Philad.), 34, 338-344.

Wolff, M. and Ahmed, N. (1976). Epithelial neoplasms of the vermiform appendix (exclusive of carcinoid): I. Adenocarcinoma of the appendix. Cancer (Philad.), 37, 2493-2510.

Wood, D. A. (1967). Tumors of the intestines. Atlas of Tumor Pathology, Section 6, Fascile 22, pp. 177, 190-191. Armed Forces Institute of Pathology Washington, D.C. 